\title{
PEMBERDAYAAN MASYARAKAT UNTUK MENCEGAH KEMATIAN BAYI : PEMINJAMAN GRATIS INKUBATOR UNTUK SELURUH NUSANTARA
}

\author{
Ibnu Roihan ${ }^{1}$, Juan Karnadi ${ }^{2}$, Arbi Riantono ${ }^{3}$ dan Raldi Artono Koestoer ${ }^{4}$ \\ ${ }^{1}$ Departemen Teknik Mesin, Fakultas Teknik, Universitas Indonesia \\ Surel: ibnu.roihan51@ui.ac.id \\ ${ }^{2}$ Departemen Teknik Elektro, Fakultas Teknik, Universitas Indonesia \\ Surel: juan.karnadi@ui.ac.id \\ ${ }^{3}$ Departemen Teknik Mesin, Fakultas Teknik, Universitas Indonesia \\ Surel: arbi.riantono01@ui.ac.id \\ ${ }^{4}$ Departemen Teknik Mesin, Fakultas Teknik, Universitas Indonesia \\ Surel: koestoer@eng.ui.ac.id
}

\begin{abstract}
One of the 17 frameworks for the Sustainable Development Goals (SDGs) program is about healthy life and encouraging prosperity for all ages. The Indonesian government, within the framework of SDGs targeting NMR, can decrease to 12 deaths per 1000 births. The existence of an incubator as a premature baby warmer device is essential. But such health facilities in the area are still lacking. The Grashof Portable Home Inkubator, one of the innovations from Universitas Indonesia, was lent free of charge as one of the product-based community engagement activities from 2012 to the present. It was lent freely to the mother's baby's home from the lower-class community. The network of volunteer agents is at the forefront of implementing this activity in many locations in Indonesia. The volunteer agents replace the primary cost production of the incubator so the problem of funds can be overcome. Socialization and collaboration with all levels of society, both individuals and institutions, is carried out so that more premature babies can be helped. From 2012 until now, this activity has helped more than 3000 babies carried out by volunteer agents who already exist in 22 provinces spread over 103 locations. This activity has increased to community empowerment, which directs or indirectly helps government programs in reducing infant mortality. Public awareness to help others, especially poor people, can make life's welfare better.
\end{abstract}

Keywords: SDGs, People Empowerment, Infant Mortality Rate, Free Lending Incubator, Grashof Incubator

\begin{abstract}
ABSTRAK
Salah satu dari 17 kerangka kerja program Sustainable Development Goals (SDGs) adalah tentang kehidupan yang sehat dan mendorong kesejahteraan bagi semua orang di segala usia. Pemerintah Indonesia dalam kerangka SDGs menargetkan angka kematian bayi / neonatal (AKB/AKN) turun menjadi 12 kematian per 1000 kelahiran. Keberadaan inkubator sebagai alat penghangat bayi prematur sangatlah penting. Namun fasilitas kesehatan seperti itu di daerah tersebut masih kurang. Inkubator Grashof Portabel yang merupakan salah satu produk inovasi dari Universitas Indonesia ini dipinjamkan secara cuma-cuma sebagai salah satu kegiatan pengabdian masyarakat berbasis produk dari tahun 2012 hingga saat ini. Inkubator dipinjamkan secara gratis ke rumah orangtua bayi dari golongan prasejahtera. Jejaring relawan menjadi garda terdepan dalam pelaksanaan kegiatan ini di banyak lokasi di Indonesia. Agen relawan mengganti biaya pokok produksi inkubator sehingga masalah dana bisa teratasi. Sosialisasi dan kerjasama dengan seluruh lapisan masyarakat baik individu maupun institusi dilakukan agar lebih banyak bayi prematur yang dapat tertolong. Sejak tahun 2012 hingga saat ini kegiatan ini telah membantu lebih dari 3000 bayi yang dilaksanakan oleh agen relawan yang sudah ada di 22 provinsi yang tersebar di 103 lokasi. Kegiatan ini meningkat menjadi pemberdayaan masyarakat, yang secara langsung maupun tidak langsung membantu program pemerintah dalam menurunkan angka kematian bayi. Kesadaran masyarakat untuk membantu sesama, terutama masyarakat pra-sejahtera dapat meningkatkan kesejahteraan hidup lebih baik.
\end{abstract}

Kata Kunci: SDGs, Pemberdayaan Masyarakat, Angka Kematian Bayi, Peminjaman Gratis Inkubator, Inkubator Grashof 


\section{PENDAHULUAN}

Bayi baru lahir dalam istilah kedokteran disebut masa neonatal. Masa neonatal dihitung sejak lahir sampai bayi berusia 28 hari (WHO, 2018). Data tahun 2017, Survei Demografi Kesehatan Indonesia (SDKI) menjelaskan bahwa angka kematian neonatal (AKN) di Indonesia mengalami penurunan. Pada tahun 2012, NMR di Indonesia mencapai 19 kasus kematian dari setiap 1000 kelahiran. Dan pada tahun 2017 menurun menjadi 15 kasus kematian dari setiap 1000 kelahiran (BKKBN, 2017). Meski secara statistik mengalami penurunan, AKN di Indonesia masih tergolong tinggi dibandingkan negara lain, khususnya tingkat ASEAN. Menurut data United Nations Children's Fund (UNICEF) tahun 2017, AKN di Thailand hanya sekitar 6 kasus kematian dari setiap 1000 kelahiran, Malaysia 5:1000, bahkan Singapura hanya 2:1000 (UNICEF, 2018b). Dalam laporan tahun 2018, UNICEF menyatakan bahwa 47\% kematian balita didominasi oleh periode neonatal (UNICEF, 2018a). Dan kasus AKN lebih sering terjadi di pedesaan daripada di perkotaan (BKKBN, 2018).

Bayi prematur membutuhkan inkubator sebagai alat penghangat untuk menjaga suhu tubuh idealnya. Fasilitas pelayanan kesehatan di Indonesia khususnya inkubator bayi belum merata hingga ke pelosok. Puskesmas di Indonesia masih lebih banyak di perkotaan. Berdasarkan data Profil Kesehatan Indonesia tahun 2018 menunjukkan bahwa jumlah puskesmas di pulau-pulau atau perdesaan masih sedikit dibandingkan di kota (RI, 2018).

Adanya hubungan erat antara status ekonomi dan ketidakberdayaan masyarakat dalam membangun kesehatan (Adler et al., 1994). Hal ini menyebabkan NMR di beberapa daerah tertinggal yang tidak mempunyai fasilitas kesehatan yang cukup lebih besar dibandingkan dengan perkotaan. Pemberdayaan masyarakat secara mandiri yang dilakukan oleh masyarakat setempat bisa menjadi solusi untuk meningkatkan kesejahteraan dalam bidang kesehatan (Wallerstein, 1993). Kegiatan yang mengikutsertakan masyarakat dalam usaha pemberdayaan, terbukti dapat membantu mengurangi kesenjangan kesehatan (Wallerstein, 2002).

Pengabdian masyarakat berupa peminjaman gratis inkubator kepada masyarakat pra-sejahtera adalah salah satu usaha dalam membantu menurunkan NMR di Indonesia. Tujuan penelitian ini adalah untuk melihat pengaruh kegiatan tersebut terhadap respon masyarakat yang menjadi pionir penggerak di masing-masing lokasi. Diharapkan dengan adanya kegiatan tersebut, bukan hanya bayi yang tertolong tetapi juga terbentuknya kepekaan masyarakat dalam mencari solusi dari masalah yang ada di sekitarnya dengan usahanya masing-masing. Sehingga kesejahteraan kesehatan, khususnya dalam membantu bayi prematur dari masyarakat pra-sejahtera, dapat ditingkatkan. Penerapan pemberdayaan masyarakat buah hasil dari pengabdian masyarakat menjadi kunci keberlanjutannya program atau aktifitas.

\section{Sustainability Development Goals (SDGs)}

Dari 17 poin kerangka kerja (framework) SDG, poin nomor tiga mengangkat topik kesehatan yang baik. Poin tersebut menjelaskan bahwa negara mempunyai andil dalam hal jaminan hidup yang sehat dan mendorong kesejahteraan bagi semua orang di segala usia (DIRJEN BINA GIZI KIA, 2017). Salah satu urusan yang belum terselesaikan pada bidang kesehatan adalah penurunan angka kematian neonatal (NMR), angka kematian bayi (AKB), dan angka kematian ibu (DIRJEN BINA GIZI KIA, 2017). Target dari pemerintah, angka kematian neonatal dapat menurun hingga 12 kematian setiap 1000 kelahiran. Tentunya perlu kerjasama antara pemerintah dan masyarakat untuk mencapai target yang ingin dicapai. 


\section{Pengabdian Masyarakat - Aktifitas Peminjaman Gratis Inkubator Bayi}

Pengabdian masyarakat berbasiskan produk dari Universitas Indonesia berupa peminjaman gratis inkubator ke rumah orangtua bayi menjadi salah satu solusi dalam menurunkan angka kematian neonatal (Raldi A Koestoer \& Roihan, 2016). Banyak faktor yang menyebabkan masyarakat menengah ke bawah tidak dapat mendapatkan fasilitas inkubator di rumah sakit. Hal yang paling umum terjadi dikarenakan keterbatasan ekonomi keluarga dalam menyewa inkubator di rumah sakit sehingga bayi dirawat di rumah dengan kondisi apa adanya (Agency, 2017; Heroes, 2017). Fasilitas kesehatan di daerah pelosok yang belum merata juga menjadi penyebab banyaknya kasus bayi prematur yang tidak tertolong.

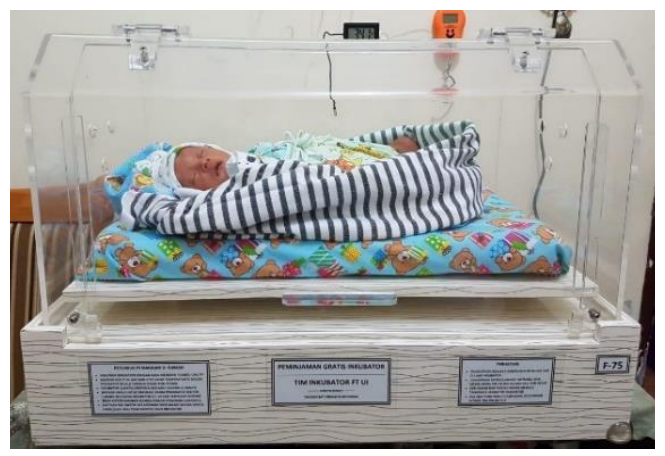

Gambar 1. Bayi Prematur Dalam Inkubator Grashof

Sumber: Dokumen Pribadi, 2019

Gambar 1 menunjukkan salah satu bayi prematur yang mendapatkan manfaat dari peminjaman gratis inkubator. Aktifitas kemanusiaan ini sudah berjalan sejak 2012 hingga sekarang. Inkubator bayi tersebut dipinjamkan secara gratis kepada masyarakat prasejahtera dan dirancang khusus untuk penggunaan di rumah (Raldi Artono Koestoer, 2018). Pelaksana kegiatan ini adalah Tim Inkubator Universitas Indonesia (TIUI) yang bukan hanya telah membuat inkubator portable, tetapi juga menjalankan peminjaman gratis kepada yang membutuhkannya. Penggunaan SMS Center sebagai database peminjaman inkubator membantu kinerja kegiatan dalam pengolahan data (Roihan, 2020).

\section{Inkubator Grashof Portable}

Portable grashof inkubator adalah alat penghangat bayi prematur atau bayi dengan berat lahir rendah. Inkubator Grashof dirancang dengan konsep green technology, antara lain penghematan konsumsi energi, material kayu organik, portabel, dan ringan. Dirancang khusus dengan hanya menggunakan dua buah lampu pijar berdaya 25 watt sebagai penghangat. Gambar 2 menunjukkan bagian-bagian inkubator grashof.

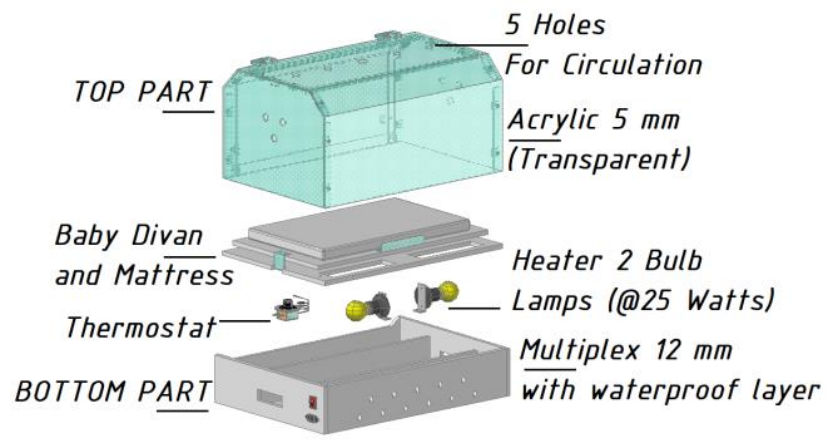

Gambar 2. Bagian-Bagian Inkubator Grashof

Sumber: Dokumen Pribadi, 2018 
Dengan berat hanya sekitar $14 \mathrm{~kg}$ menjadikan alat ini mudah dibawa melewati medan yang sulit. Dimensi yang ringkas menjadikan dapat ditempatkan di ruangan yang kecil sekalipun. Prinsip kerja menggunakan konveksi alami sehingga tidak ada suara bising di dalam kabin (Raldi Artono Koestoer, Roihan, \& Andrianto, 2019). Inkubator tersebut sudah melalui uji untuk dapat sesuai dengan standar yang diberlakukan agar didapatkan produk yang berkualitas (Septiana, Roihan, \& Koestoer, 2020; Zaelani, Koestoer, Roihan, \& Harinaldi, 2019).

\section{Pemberdayaan Masyarakat}

Pemberdayaan masyarakat adalah proses perubahan yang interaktif, di mana institusi dan komunitas menjadi bertransformasi menjadi orang-orang yang berpartisipasi dalam perubahan tersebut (Wallerstein \& Bernstein, 1994). Partisipasi masyarakat sangat berpengaruh dalam mewujudkan pemberdayaan masyarakat, dalam hal ini mengenai kesehatan (De Vos et al., 2009; Heritage \& Dooris, 2009). Ketidakberdayaan masyarakat pra-sejahtera perlu dibantu oleh masyarakat mampu di sekitarnya. Dengan mengetahui kearifan lokal dari aspek budaya, bahasa, dan lainnya, masyarakat lebih mudah menerima masukan atau arahan dari warga lokal dibandingkan dengan masyarakat dari luar (Cahyaningrum, 2017).

\section{METODE PELAKSANAAN PKM}

\section{Agen Relawan}

Pada tahun pertama aktifitas ini, mulai 2012 hingga 2013, bayi prematur yang mendapat bantuan peminjaman gratis inkubator masih sedikit. Hal tersebut karena keterbatasan daerah yang dapat dijangkau dan jumlah inkubator pada saat itu yang tidak banyak. Setelah muncul dalam berita di salah satu media elektronik (News, 2013), banyak masyarakat yang mau membantu kegiatan tersebut di daerahnya masing-masing. Masyarakat yang mau membantu ini disebut agen relawan.

Gotong royong adalah kunci dari kegiatan ini. Agen relawan adalah orang-orang biasa yang ingin membantu program peminjaman inkubator gratis atas kemauan mereka sendiri tanpa ada paksaan. Peran serta agen relawan juga menjembatani program ini dengan pihak professional dan petugas medis yang lebih tahu kondisi di lapangan, sehingga menjadi sebuah jejaring kebermanfaatan dalam masyarakat.

Inkubator ini tidak dijual. Dan untuk mendapatkan inkubator tersebut dalam rangka membantu bayi prematur di daerah masing-masing adalah dengan cara kerjasama dengan amanah.

Ada empat amanah utama jika masyarakat atau agen relawan mau membantu program ini. Pertama, mengganti biaya produksi satu unit inkubator sebesar Rp 4.000.000. Dengan kata lain, Tim Inkubator UI menerima amanah untuk menjadikan dana tersebut menjadi inkubator yang siap digunakan di wilayah agen relawan berada. Sehingga tidak ada masalah keuangan dalam membuat inkubator tersebut.

Amanah kedua adalah agen relawan tidak boleh mengkomersialkan inkubator tersebut dalam penggunaannya. Tujuan aktifitas ini adalah membantu masyarakat pra-sejahtera yang secara perekonomian sangat rendah. Ketiga, calon agen relawan bersedia mengantarkan inkubator tersebut ke rumah orangtua bayi dan menjemputnya kembali saat bayi sudah sehat. Masyarakat pra-sejahtera tentunya tidak mempunyai fasilitas kendaraan yang dapat membawa inkubator tersebut dengan aman. Oleh karena itu agen relawan diamanahkan hal tersebut. Dengan mengantarkannya, agen relawan tahu persis dengan kondisi masyarakat yang dibantunya, sehingga diharapkan tumbuh kepeduliaan antar sesama.

Dan amanah yang terakhir adalah memelihara inkubator tersebut. Kebersihan dan kerusakan menjadi tanggung jawab agen relawan, bukan peminjam (orangtua bayi). Setelah dipinjam oleh 
satu keluarga bayi prematur yang sudah sehat, inkubator harus dipelihara agar siap digunakan secara optimal untuk bayi prematur lainnya (Raldi Artono Koestoer, 2015).

Metode ini merupakan implementasi pemberdayaan masyarakat setelah adaya kegiatan pengabdian masyarakat dari pihak universitas. Metode ini dibuat sebagai salah satu upaya dalam keberlanjutan kegiatan ini agar dapat terlaksana secara mandiri di mayarakat.

\section{HASIL DAN PEMBAHASAN}

\section{Hasil}

Mulai tahun 2014, beberapa masyarakat atau agen relawan dari berbagai lokasi di Indonesia bergabung dalam aktifitas peminjaman gratis inkubator. Gambar 3 menunjukkan pertumbuhan jumlah agen relawan setiap tahun hingga September 2019.

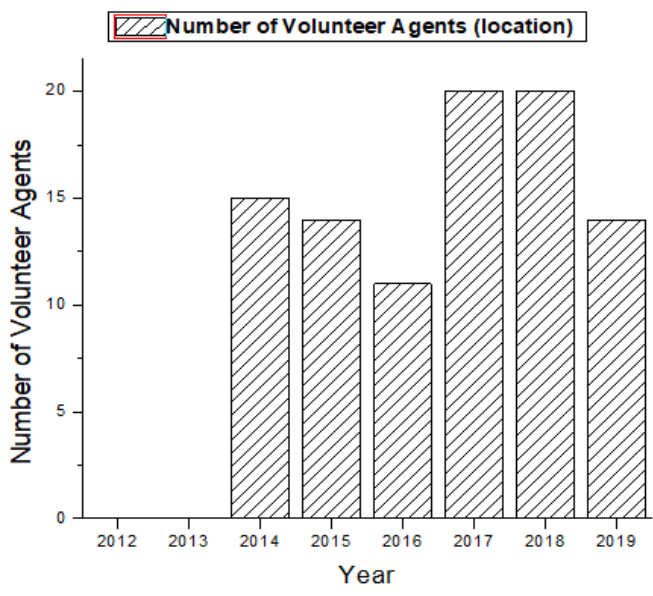

Gambar 3. Perkembangan Jumlah Agen Relawan Peminjaman Gratis Inkubator

Pada tahun 2012 hingga 2013 belum ada agen relawan yang bergabung karena aktiftas ini belum dikenal oleh khalayak ramai. Setelah kegiatan ini diliput banyak media mulai tahun 2014 hingga sekarang, beberapa masyarakat tertarik untuk melaksanakan pemberdayaan masyarakat ini. Pertumbuhan jumlah agen relawan tidak menunjukkan tren yang meningkat setiap tahunnya. Hingga bulan September 2019 tercatat sudah ada 94 agen relawan atau lokasi yang tersebar di 20 provinsi di Indonesia. Dan data terbaru di bulan September 2020 sudah bertambah menjadi 22 provinsi di 103 lokasi. Jumlah tersebut belum mencapai target yang ingin dicapai yaitu sekitar 300-400 kota/kabupaten di seluruh Indonesia.

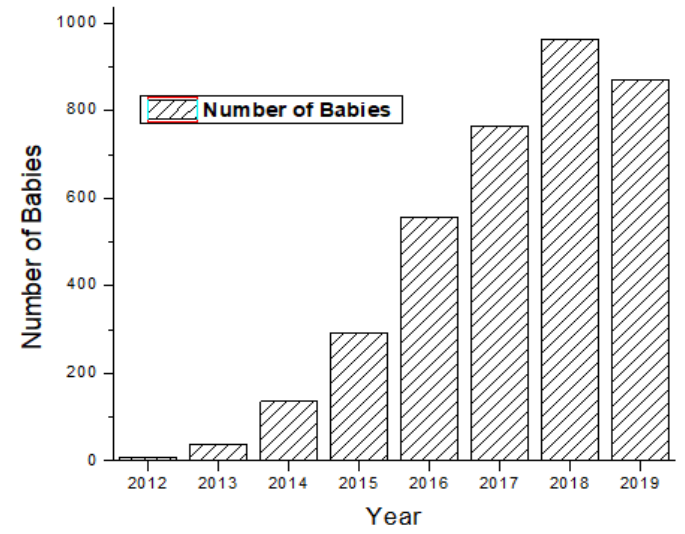

Gambar 4. Jumlah Bayi yang Telah Dibantu (Data Hingga September 2019) 
Gambar 4 menunjukkan perkembangan setiap tahun jumlah bayi yang telah memanfaatkan peminjaman gratis inkubator. Jumlah dari tahun ke tahun semakin meningkat seiring dengan bertambahnya agen relawan yang membantu bayi prematur. Keinginan agen relawan dalam menambah unit inkubator juga berdampak kepada semakin banyaknya bayi yang dapat terbantu. Penambahan unit berdasarkan keinginan mereka sendiri karena melihat banyaknya bayi prematur yang perlu dibantu di sekitarnya. Hal tersebut diketahui setelah adanya peminjaman dan info mulai tersebar ke khalayak ramai. Sejak tahun 2012 hingga September 2019, sudah ada lebih dari 3000 bayi prematur dan bayi kuning yang telah menerima manfaat dari kegiatan ini.

\section{Pembahasan}

Dari kegiatan ini, banyak dampak positif yang muncul. Pemberdayaan masyarakat berjalan dengan adanya agen relawan yang turut serta dalam menolong bayi prematur. Tidak hanya individual yang menjadi agen relawan. Entitas dari agen relawan berkembang seiring dengan kearifan local dari setiap daerah. Mulai dari individual, pasangan suami-istri, keluarga utuh, bidan desa, komunitas anak muda, klinik, rumah sakit, hingga instansi atau lembaga, semuanya bahu membahu dalam membantu kegiatan ini.

Gambar 5 hingga 8 menunjukkan berbagai macam entitas agen relawan yang tergabung dalam aktifitas peminjaman gratis inkubator. Salah satu agen relawan dari entitas individual adalah Dimas Riszaldi dari wilayah Kediri Jawa Timur. Sejak Desember 2016 memantapkan untuk bergabung menjadi agen relawan. Dimas mempunyai 2 unit inkubator yang dapat dipinjamkan dan hingga sekarang sudah lebih dari 20 keluarga bayi prematur yang telah dibantunya (Muchamad, 2018).

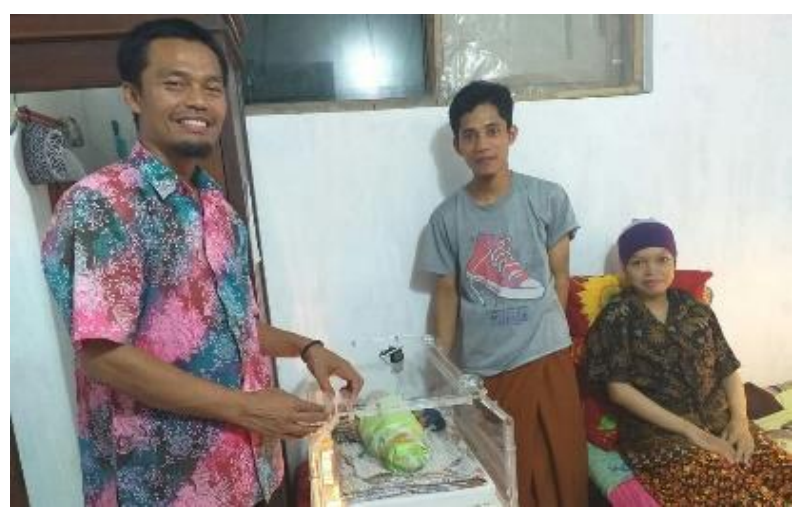

Gambar 5. Agen Relawan Kudus Jawa Tengah (Budiyono) Bersama Keluarga Bayi Prematur

Sumber: ISKNews, 2019

Gambar 5 menunjukkan agen relawan lainnya dari wilayah Kudus Jawa Barat, Budiyono, yang telah bergabung sejak Januari 2017. Keinginan untuk bergabung dalam aktifitas tersebut hanya supaya dapat bermanfaat bagi masyarakat sekitar, khususnya menolong bayi prematur dari masyarakat pra-sejahtera (MR, 2019). Hal yang sama dirasakan oleh Delima sebagai agen relawan dari wilayah Pamulang, Jakarta Selatan. Sejak bergabung November 2018 telah memiliki 5 unit inkubator yang dapat dipinjamkan secara gratis. Keikutsertaannya didasari karena melihat ibu bayi prematur yang kesulitan akan biaya rumah sakit dan keinginannya merawat di rumah (Deniansyah, 2019).

Tidak hanya individual, pasangan suami-istri pun dengan kompak menjadi agen relawan dalam membantu bayi prematur. Gambar 6 menunjukkan Sudarsono dan Yulian (kanan dan tengah), agen relawan dari wilayah Malang, sejak Februari 2017 sudah menolong lebih dari 50 bayi prematur. Yulian yang berlatar belakang kesehatan bahkan memberi edukasi kepada orangtua bayi prematur bagaimana cara merawatnya (Arshita, 2019). Contoh lainnya adalah Lugi dan Enny, sebagai 
pasangan suami-istri yang bergabung sejak Februari 2015 telah memiliki 10 unit inkubator. Lebih dari 150 bayi telah merasakan manfaat dari inkubator yang dikelola oleh pasangan suami-istri tersebut. Sebagai pegiat sosial, hidupnya diabdikan salah satunya sebagai agen relawan (Jayanti, 2019a). Bahkan pemberdayaan masyarakat yang telah dilakukannya telah berkembang bukan hanya menolong bayi prematur dengan meminjamkan gratis inkubator. Pasangan suami-istri ini juga meminjamkan gratis kursi roda kepada masyarakat yang membutuhkannya (Jayanti, 2019b).

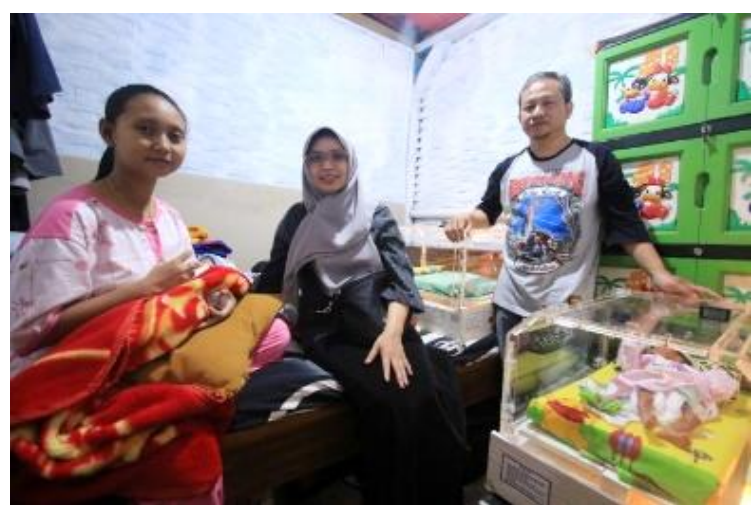

Gambar 6. Agen Relawan Malang Jawa Timur (Sudarsono) Bersama Keluarga Bayi Prematur Sumber: Radar Malang, 2019

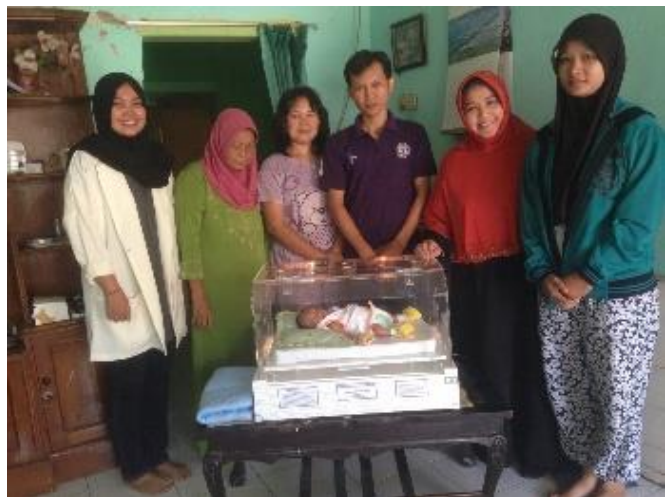

Gambar 7. Agen Relawan Surabaya Jawa Timur (Keluarga Bapak Adji Dan Ibu Lutfia) Bersama Keluarga Bayi Prematur

Sumber: Dokumen Pribadi, 2019

Gambar 7 menunjukkan entitas lembaga relawan berupa satu keluarga. Entitas agen relawan berupa keluarga utuh antara keluarga Adji dan Lutfia. Keikutsertaan ketiga anaknya dalam membantu bayi prematur dilakukannya dengan sepenuh hati. Dengan kolaborasi tersebut dapat saling membantu saat dimana ada yang berhalangan untuk ikut serta dalam mengantarkan inkubator. Sejak bergabung pada Juli 2015 telah membantu lebih dari 110 keluarga bayi prematur dengan 6 unit inkubator yang dimilikinya. Dorongan yang kuat menjadi agen relawan didasarkan oleh ingin bermanfaat untuk orang banyak dalam jangka waktu panjang (GRC, 2018).

Komunitas anak muda yang banyak muncul pada zaman sekarang juga ikut serta dalam membantu bayi prematur. Salah satu contohnya adalah Zona Bombong. Komunitas yang sudah terbentuk sejak lima tahun lalu banyak melakukan kegiatan sosial kepada masyarakat (Bronto, 2018). Jaringan yang luas yang dimiliki oleh komunitas ini membuat jarak bukan masalah. Peminjaman 
dilakukan secara estafet dan saling membantu untuk menolong bayi prematur yang lokasinya jauh (Karnadi, 2017; Raldi Artono Koestoer, 2017)

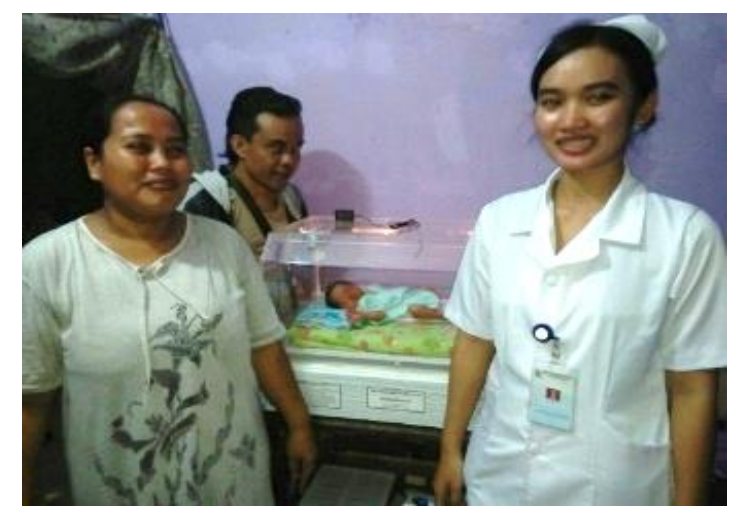

Gambar 8. Agen Relawan Pemalang Jawa Tengah (Rumah Sakit Santa Maria) Bersama Keluarga Bayi Prematur

Sumber: Dokumen Pribadi, 2019

Klinik dan rumah sakit pun dapat menjadi agen relawan seperti yang dapat dilihat pada Gambar 8 . Dengan visi dan misi yang sama yaitu menolong bayi prematur, sudah ada lima rumah sakit yang bekerja sama dalam meminjamkan secara gratis inkubator ke rumah orangtua bayi. Semua bentuk entitas agen relawan membuktikan bahwa pemberdayaan masyarakat bias dilakukan oleh siapapun dengan bentuk apapun. Tujuan ini selaras dengan program pemerintah dalam kerangka SDG's yang salah satu targetnya adalah menurunkan angka kematian neonatal. Bukan hanya bayi prematur yang menjadi sehat, keluarga bayi juga ikut senang dengan adanya kegiatan ini. Dengan adanya kegiatan ini, energy positif dalam bermasyarakat dapat tumbuh dan menyebar dengan sendirinya.

\section{KESIMPULAN}

Keberlanjutan dari pengabdian masyarakat salah satunya dengan cara bagaiamana diterapkannya pemberdayaan masyarakat. Peminjaman gratis inkubator untuk nusantara telah membuktikan hal tersebut. Tertransformasinya kesadaran, komitmen, kemauan, pengetahuan, keterampilan, dan afeksi dari masyarakat kepada masyarakat lainnya menjadi bukti indicator peningkatan pemberdayaan masyarakat. Dengan kepedulian masyarakat terhadap upaya penyelamatan bayi prematur, secara langsung dan tidak langsung dapat membantu program pemerintah di kerangka SDG's yang salah satunya adalah menurunkan angka kemarian neonatal di Indonesia. Masih diperlukan lebih banyak agen relawan di setiap daerah untuk menolong lebih banyak bayi prematur. Mari bergotong royong untuk Indonesia yang lebih baik.

\section{Ucapan Terima Kasih (Acknowledgement)}

Pekerjaan ini didukung oleh "2020 Community Engagement Grants" yang didanai oleh Direktorat Pengabdian dan Pemberdayaan Masyarakat Universitas Indonesia No: 248 /UN2.PPM/HKP.05.00/2020

\section{REFERENSI}

Adler, N. E., Boyce, T., Chesney, M. A., Cohen, S., Folkman, S., Kahn, R. L., \& Syme, S. L. (1994). Socioeconomic status and health: the challenge of the gradient. American Psychologist, 49(1), 15. 
Agency, A. N. (2017). Free inkubators save lives of Indonesian babies. Retrieved February 10, 2020, from https://www.youtube.com/watch?v=s10rc-Dqy0c

Arshita, E. V. (2019, August). Sudarsono, Relawan Peminjaman Inkubator Gratis. Tiga Tahun "Selamatkan" Nyawa 50 Bayi Prematur. Jawa Pos. Radar Malang, p. 7. Retrieved from https://radarmalang.id/tiga-tahun-selamatkan-nyawa-50-bayi-prematur/

BKKBN. (2017). Tren Angka Kematian Neonatal, Kematian Bayi, dan Kematian Balita, SDKI 1991-2017. Retrieved from https://e-koren.bkkbn.go.id/wpcontent/uploads/2018/10/Leaflet-SDKI-2017.pdf

BKKBN. (2018). Survei Demografi dan Kesehatan Indonesia 2017 (Puslitbang Kependudukan BKKBN, Ed.). Retrieved from http://sdki.bkkbn.go.id/files/buku/2017IDHS.pdf

Bronto, S. (2018). Gus Abror Selalu Ada Jalan saat Ikhlas Menolong. Retrieved September 30, 2019, from Media Indonesia website: https://mediaindonesia.com/read/detail/187271-gusabror-selalu-ada-jalan-saat-ikhlas-menolong

Cahyaningrum, D. (2017). Community Empowerment Based Local Wisdom In Tourism Of Bajo Community, Wakatobi. International Journal Of Scientific \& Technology Research, 6(11), 196-201.

De Vos, P., De Ceukelaire, W., Malaise, G., Pérez, D., Lefèvre, P., \& Van der Stuyft, P. (2009). Health through people's empowerment: a rights-based approach to participation. Health and Human Rights, 23-35.

Deniansyah, R. (2019). Bayi Lahir Prematur, di Tangsel Ada Peminjaman Inkubator Gratis. Retrieved September 30, 2019, from http://tangerangnews.com/tangsel/read/26065/BayiLahir-Prematur-di-Tangsel-Ada-Peminjaman-Inkubator-Gratis

DIRJEN BINA GIZI KIA. (2017). KESEHATAN DALAM KERANGKA SUSTAINABLE DEVELOPMENT GOALS (SDGs). Retrieved February 4, 2020, from http://sdgs.bappenas.go.id/wp-content/uploads/2017/09/Kesehatan-Dalam-KerangkaSDGs.pdf

GRC. (2018, December). Selamatkan Puluhan Nyawa Lewat Inkubator Bayi. Majalah Yatim Mandiri, $28-29$.

Retrieved

from

http://yatimmandiri.org/index.php/Welcome/lihat/inspirasi/13/Adji-Pramudya---

Selamatkan-Puluhan-Nyawa-Bayi-Lewat-Inkubator-Gratis

Heritage, Z., \& Dooris, M. (2009). Community participation and empowerment in Healthy Cities. Health Promotion International, 24(suppl_1), i45-i55.

Heroes, Z. L. (2017). No place like home: The man saving prematur babies.

Jayanti, N. U. (2019a). Kisah Pasutri Pelopor Peminjaman Inkubator Gratis di Bogor. Retrieved September 30, 2019, from https://health.detik.com/berita-detikhealth/d-4707112/kisahpasutri-pelopor-peminjaman-inkubator-gratis-di-bogor

Jayanti, N. U. (2019b). Pasutri Relawan Inkubator di Bogor Juga Pinjamkan Kursi Roda Gratis. Retrieved September 30, 2019, from https://health.detik.com/berita-detikhealth/d4708104/pasutri-relawan-inkubator-di-bogor-juga-pinjamkan-kursi-rodagratis?_ga=2.21787321.327985360.1568769659-121541016.1562720706

Karnadi, J. (2017). Kolaborasi. Retrieved September 30, 2019, from http://www.inkubatorgratis.org/2017/03/14/kolaborasi/

Koestoer, Raldi A, \& Roihan, I. (2016). Unpatented grashof-inkubator as a part of communityenggagement in mechanical engineering university of Indonesia. Prosiding SENTRA (Seminar Teknologi Dan Rekayasa), (2).

Koestoer, Raldi Artono. (2015). PERSYARATAN AGEN RELAWAN. Retrieved February 1, 
2019, from https://koestoer.wordpress.com/2015/09/29/persyaratan-agen-relawan/

Koestoer, Raldi Artono. (2017). ESTAFET INKUBATOR PURWOKERTO-TASIKMALAYA. Retrieved September 30, 2019, from https://koestoer.wordpress.com/2017/03/12/estafetinkubator-purwokerto-tasikmalaya/

Koestoer, Raldi Artono. (2018). Free Lending Home Inkubator as a Community Engagement for All. Rising to the Challenge of SDGs in Asia through University-Community Engagement Book of Abstract, 62. Retrieved from http://asiaengage2018.cmu.ac.th/uploads/Book_of_Abstracts.pdf

Koestoer, Raldi Artono, Roihan, I., \& Andrianto, A. D. (2019). Product design, prototyping, and testing of twin inkubator based on the concept of grashof inkubator. AIP Conference Proceedings, 2062(1), 20013. AIP Publishing.

MR. (2019). BUDIYONO BERBAGI MANFAAT PINJAMKAN INKUBATOR BAYI. Retrieved September 30, 2019, from https://isknews.com/budiyono-berbagi-manfaatpinjamkan-inkubator-

bayi/?fbclid=IwAR2NebFrKz6y6GbjbGxCLzK1Y1H63Z3cQ3Gjt7K_9gj98ZE1dBYhh8v 4 h68

Muchamad, Y. (2018, July). Dimas Riszaldi, Relawan Inkubator Gratis. Gotong Royong untuk Bayi Prematur. Koran Memo Kediri, p. 13. Retrieved from http://www.inkubatorgratis.org/2018/08/08/gotong-royong-untuk-bayi-prematur/

News, O. N. (2013). IMS - Inkubator rumahan dipinjamkan gratis. Retrieved September 30, 2019, from https://www.youtube.com/watch? $=\mathrm{vDV}$ oIce $4 \mathrm{kWE}$

RI, K. (2018). DATA DAN INFORMASI PROFIL KESEHATAN INDONESIA 2018. Retrieved from http://www.depkes.go.id/resources/download/pusdatin/profil-kesehatanindonesia/Data-dan-Informasi_Profil-Kesehatan-Indonesia-2018.pdf

Roihan, I. (2020). SMS Center Inkubator. Retrieved from http://yabapi.zenziva.net

Septiana, R., Roihan, I., \& Koestoer, R. A. (2020). Development of portable grashof inkubator type A up to $\mathrm{H}$ using digital thermostat W1209 to improve heat performance according to SNI IEC 60601-2-19: 2014 criteria. AIP Conference Proceedings, 2248(1), 50003. AIP Publishing LLC.

UNICEF. (2018a). Levels \& Trends in Child Mortality. Retrieved August 19, 2019, from https://www.unicef.org/publications/index_103264.html

UNICEF. (2018b). Neonatal mortality rate. Retrieved August 19, 2019, from https://data.unicef.org/topic/child-survival/neonatal-mortality/

Wallerstein, N. (1993). Empowerment and health: the theory and practice of community change. Community Development Journal, 28(3), 218-227.

Wallerstein, N. (2002). Empowerment to reduce health disparities. Scandinavian Journal of Public Health, 30(59_suppl), 72-77.

Wallerstein, N., \& Bernstein, E. (1994). Introduction to community empowerment, participatory education, and health. Sage Publications Sage CA: Thousand Oaks, CA.

WHO. (2018). Newborns: reducing mortality. Retrieved August 19, 2019, from https://www.who.int/en/news-room/fact-sheets/detail/newborns-reducing-mortality

Zaelani, A. V., Koestoer, R. A., Roihan, I., \& Harinaldi. (2019). Analysis of temperature stabilization in grashof inkubator with environment variations based on Indonesian national standard (SNI). AIP Conference Proceedings, 2062(1), 20003. AIP Publishing. 